\title{
An innovative metallic microfluidic device for intensified biodiesel production
}

José M. Costa Junior ${ }^{1,2}$, Carolina P. Naveira-Cotta $\left({ }^{*}\right)$, Diego B. de Moraes ${ }^{l}$, Paulo Inforçatti Neto ${ }^{3}$ Izaque A. Maia ${ }^{3}$, Jorge V. L. da Silva ${ }^{3}$,Haimon Alves ${ }^{4}$, Manish K. Tiwari $^{5}$, Cristiane G. de Souza ${ }^{6}$

${ }^{1}$ Laboratory of Nano \& Microfluidics and Microsystems - LabMEMS

Mechanical Eng. Dept and Eng. of Nanotechnology Dept. - Federal University of Rio de Janeiro - UFRJ, Rio de Janeiro, RJ, Brazil

${ }^{2}$ Federal Institute of Sertão Pernambucano - IFSERTÃO-PE - Campus Serra Talhada Rodovia PE 320, CEP: 56912-140, Serra Talhada, PE, Brazil

${ }^{3}$ Three-Dimensional Division, Renato Archer Information Technology Center - CTI, Campinas, SP, Brazil

${ }^{4}$ Physics Institute - State University of Rio de Janeiro - UERJ, Rio de Janeiro, RJ, Brazil

${ }^{5}$ Nanoengineered Systems Laboratory, UCL Mechanical Engineering, University College London, London, WC1E 7JE, UK ${ }^{6}$ Laboratory of Fuels and Petroleum Derivatives - LabCOM

School of Chemistry - Federal University of Rio de Janeiro - UFRJ, Rio de Janeiro, RJ, Brazil

(*) Corresponding author: Email - carolina@mecanica.coppe.ufrj.br 


\section{Abstract}

We present a strategy for intensified biodiesel production in a novel metallic microdevice. Additive manufacturing using Selective Laser Melting (SLM) was employed to build the metallic device consisting of multiple micro reactors monolithically integrated with multiple micro heat exchangers. This device allows high conversion rate of biodiesel production with concomitant use of the rejected heat from external source to enhance the reaction temperature and, thereby, its output.

The biodiesel production was carried out using soybean oil, ethanol and $\mathrm{NaOH}$ as the catalyst. The influences of the reaction temperature and the residence time in the biodiesel production was examined. Biodiesel yield increased with the reaction temperature and a rate of conversion of $99.6 \%$ was achieved with a reactor residence time of less than 35 seconds. The work opens up a pathway to exploit waste heat to intensify biodiesel production and contribute significantly to global sustainability. 


\section{Introduction}

Concerns about the cost of petroleum and reduction of its reserves, in addition to, perhaps even more dire, the associated environmental problems have motivated a very frantic search for suitable alternative fuel sources such as biodiesel..$^{1-4}$ Biodiesel is an alternative to the petrochemically sourced diesel because they are typically biodegradable, non-toxic and presents low carbon and sulfur content and when burned emits less particulate and unburned hydrocarbon emissions. ${ }^{1,5,6}$ In addition, biodiesel is considered a source of renewable energy that can totally or partially replace diesel produced from petroleum because biodiesel has energetic properties similar to diesel. ${ }^{6}$

Biodiesel is commonly produced commercially by the transesterification reaction of a vegetable oil, frying oil or animal fat with short chain alcohols such as methanol or ethanol, using catalysts that can be basic, acidic or enzymatic., ${ }^{2,37}$ The commercial transesterification process is performed in conventional batch reactors at high residence times (from one hour to several hours)., ${ }^{4,-10}$ The high residence time in this process led to the development of studies to reduce it and consequently increase the process efficiency. ${ }^{4,11-17}$

Several types of reactors are being developed aimed at improving the efficiency of biodiesel production. Among these reactors we can highlight those based on microscale fluidic features such as microchannels, microcylinders, microgrooves etc., which are also called micro reactors. Micro reactors appear as a promising alternative technology to improve efficiency in biodiesel production by reducing reaction times. These reactors are composed of microchannels with transversal sections presenting different geometries and with hydraulic diameters smaller than $1 \mathrm{~mm}$. These devices can achieve rapid reaction 
rates due to the short diffusion distances and high surface area/volume ratio, which improves ('intensifies') heat and mass transfer., ${ }^{6,14-24}$

The high efficiency of the biodiesel synthesis obtained via transesterification reaction using micro reactor technology was demonstrated by several authors, where high conversion rates were reached even in extremely low residence times. ${ }^{3,7,10,13-17,25-32}$

The alcohols that are most frequently used in the transesterification process are methanol and ethanol because of their low cost, availability and their physical and chemical properties. ${ }^{33}$ Most of the studies that perform the synthesis of biodiesel through the transesterification reaction in micro reactors use methanol as alcohol ${ }^{3,7,10,13,14,17,24-26,28}$, while a few studies use ethanol. ${ }^{27,29-31}$ Methanol, aside from being toxic, is usually produced from petrochemical materials, while ethanol is produced from biomass. ${ }^{34}$ Thus, biodiesel produced from ethanol is completely derived from renewable sources..$^{27,34,35}$ In addition, Brazil is one of the largest ethanol producers in the world ${ }^{36}$ Due to these characteristics, ethanol was chosen to be used in the present study.

Commonly, in biodiesel transesterification reaction three types of catalyst can be used: basic, acidic and enzymatic..$^{2,416}$ Homogeneous basic catalysts, such as sodium hydroxide $(\mathrm{NaOH})$ and potassium hydroxide $(\mathrm{KOH})$, are more commonly used because the transesterification reaction is generally faster, less expensive and more complete with these bases than with the acidic catalysts such as sulfuric acid, phosphoric acid and hydrochloric acid. ${ }^{35,37}$ Enzymatic catalysts can prevent the formation of soap (carboxyl acid), obtained through the saponification reaction of a vegetable oil (triglyceride) in the presence of a base (for example: a basic catalysts), when there is moisture in the biodiesel production process. However, commercial use of enzymes is limited due to longer reaction times and higher cost. ${ }^{2}$ Based on these considerations in this work the homogeneous basic catalyst sodium hydroxide $(\mathrm{NaOH})$ was used. 
Generally, increasing the production of biodiesel, or any other chemical, when using conventional batch reactors would entail enlarging the reactor dimensions which can be a complex, costly and time-consuming process. An alternative consists of assembling various micro reactors in a micro or minichemical plant..$^{38-46}$ This approach requires smaller floor space and energy consumption and opens up the possibility of a portable biofuel production capability. However, the approach has not been easy to realize due primarily to the limitations of the materials and/or manufacturing processes used so far to build the micro reactors; this has limited the required proof of concept and/or parametric analyses at the laboratory bench scales.

In addition to size reduction, as is well known, increasing the reaction temperature improves reaction efficiency. In general, the thermal intensification of micro reactors is done using thermal baths,,$^{3,7,10,45}$ ovens $^{27}$ or even by exploiting Joule heating through electrical resistors. ${ }^{30,41,46,47}$ In the present work, in addition to targeting a micro reactor assembly that is more portable and closer to an industrial application, we aim to substitute the thermal baths, ovens and/or electrical resistor with an integrated micro heat exchanger unit, interfaces directly with the micro reactor device. This allows utilizing waste heat from any external source to increase the reaction temperature and, thereby, its output while simultaneously enabling significant improvement of overall, systemic energy efficiency of the biodiesel synthesis process. It is well known that low grade heat $(<100$ ${ }^{\circ} \mathrm{C}$ ) is rarely useable in industrial processes. Our integration of the micro heat exchangers and micro reactors offers an excellent opportunity for low grade heat recovery, particularly because the desired temperatures for enhancing the transesterification reaction in biodiesel synthesis is $<60{ }^{\circ} \mathrm{C}$. The waste heat recovery process will benefit from metallic microdevices. 
Furthermore, with an eye on the industrial application, the metallic microdevices also features a number of excellent practical advantages such as mechanical durability, high thermal conductivity and chemical stability. The most commonly used techniques for producing microchannels on metallic substrates are based on subtractive manufacturing: micro milling, electrical discharge and laser ablation, where the sealing step is awkward, especially when dealing with many layers assembled together. ${ }^{48}$ In this context, additive manufacturing (also called 3D printing) is an appealing alternative for building microdevices with complex geometries at high resolutions and in relatively short manufacturing times. In addition, the whole fabrication can be performed on a single substrate, avoiding the need of sealing and joining steps. This feature offers an excellent advantage in terms of numbering-up, i.e., scaling the benefits of individual micro reactors and channels for maintaining the process intensification efficiencies. Similar to the recent work of Lopes et al., ${ }^{46}$ where due consideration was given to numbering up mini reactors, in this work, we will pay focused attention to this issue.

In recent literature, we can find a number of examples of the micro reactors manufactured by 3D printing. ${ }^{49-54}$ However, most of them made of polymeric materials ${ }^{49-}$ ${ }^{51}$ and some in metallic ones. ${ }^{52-54}$ In fact, despite the polymeric substrate and the reduced number of reactors (only four), Lopes et al ${ }^{46}$ were first to use $3 \mathrm{D}$ printing to manufacture a microchemical plant. To the best of our knowledge, no prior work has reported additive manufacturing of metallic material to build a microchemical plants. In the metal additive manufacturing, the Selective Laser Melting (SLM) technique stands out since it is a fast technique that produces parts with relatively higher dimensional accuracy, lower roughness and greater geometric complexity. A distinctive advantage of SLM to build devices containing long and complex microchannels structures in comparison to the other additive manufacturing technologies, such as DLP, FDM, EBM, SLS etc., is that the metal 
powder that also function as support material can be removed efficiently, clearing the microchannels and allowing the fluid to flow.

In this work it is presented the construction and characterization of an innovative microfluidic device for biodiesel production built completely in metal using additive manufacturing. The device consists of multiple micro reactors stacked and intercalated with multiple micro heat exchangers monolithically integrated, i.e., this integration (in a form of a metallic block) occurs without using any assembling resources such as glue, screws, wire, etc. Each micro reactor layer contains microchannels where the continuous flow reactions take place. We propose this novel microfluidic device to demonstrate the feasibility of parallelized, high-throughput production of biodiesel while simultaneously facilitating the use the rejected heat from an external source to enhance the reaction temperature. This device was named as Micro Monolithic Integrated Reactor and Heat Exchanger ( $\mu \mathrm{MIRHE})$. The majority of device performance assessment presented focuses on tuning the device geometry, dimensions and its influence on the efficiency of biodiesel production. The effects of residence time and reaction temperature on biodiesel production were also analyzed thoroughly.

\section{Design and manufacture of the $\mu \mathrm{MIRHE}$}

\subsection{Configuration of the micro reactor}

The $\mu$ MIRHE consists of 10 micro reactors and 11 micro heat exchangers (Fig 1), both based on microchannels having square section of 400 x $400 \mu \mathrm{m}$. Figure 1a shows a schematic external view of the complete reactor device and Figure $1 \mathrm{~b}$ illustrates the arrangement of microchannels of the micro reactors and the micro heat exchangers, detailing the entire internal structure region that will be occupied by the fluids (in blue 
the water region, and in yellow the biodiesel reactants region). Figures $2 \mathrm{a}$ and $2 \mathrm{~b}$ present in detail the design and dimensions of each micro reactor and each micro heat exchanger, respectively. The microchannel in each micro reactor has a length of $432 \mathrm{~mm}$, and each microchannel in the heat exchanger is $34 \mathrm{~mm}$ long (c.f. Fig. 2a and 2b). The $\mu$ MIRHE device is connected to the fluid driver units through three input and two output connections. All of these five connections consist of two parts: pins and Y shaped plenums. The pins split into microchannels inside the plenums. Also, these five connections dispense liquids as the following manner: two of them feeds the respective reactants (alcohol and oil) to the mixing entrance of each micro reactor, one feeds the heated liquid to the entrance of each micro heat exchanger, one for biodiesel output and finally the last one for the exit of the heating liquid.

Our primary objective in this work was to establish a proof-of-concept for a metallic microdevices which not only demonstrates process intensified biodiesel production but also demonstrates the feasibility of numbering up and exploitation of waste heat reuse in the process intensification process. To this end, it is worth highlighting that a reduced channel cross-sectional area and/or a more complex 3D structure of the channel might in fact an enhanced molecular diffusive effect. However, it is quite difficult or, in many cases, impossible to obtain clean microchannels in devices built without sealing techniques. Any reduction in dimension or increment in the geometric complexity of the channel design is offset by limitations on the fabrication process: the non-sintered powder, that serves as an inner support during the fabrication, needs to be completely removed from the channels in the cleaning (final) step of the fabrication in order to accommodate fluid flow. The dimension and precision of microchannels is closely related to the characteristics of SLM printer such as laser power, laser spot diameter, type of metal powder employed (physical/chemical properties and particle size), rastering model, 
powder layer thickness, etc. Therefore, based on the available printer and for the optimal ease of cleaning the support material from inside the channel, a $400 \mu \mathrm{m} \times 400 \mu \mathrm{m}$ (square cross-section) micro reactor was chosen.
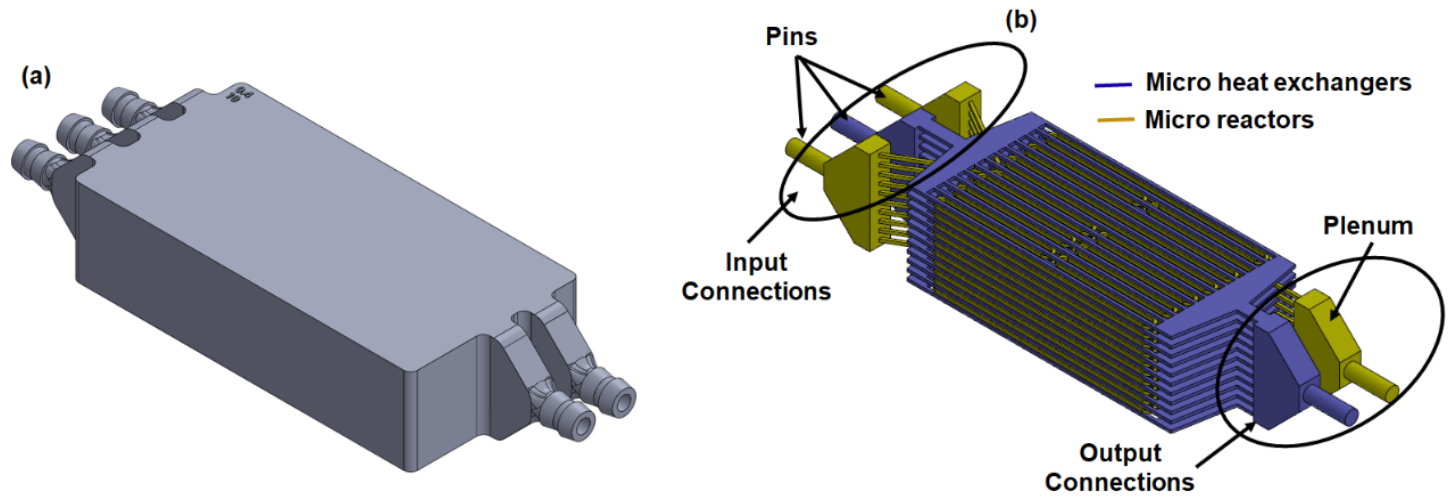

Figure 1. Schematic view of the complete $\mu$ MIRHE showing: (a) the external view of the device and (b) the internal structure of the micro reactors, the micro heat exchangers and the connections (pins and plenums).

In the $\mu$ MIRHE micro reactors are arranged in parallel and interleaved by the micro heat exchangers forming a monolithically integrated system that contributes to reduce thermal contact resistance, improving reuse of rejected heat from other processes thus enabling heating of the transesterification reaction. Finally, the flat design of the device and positions of the inlet and outlet ports took into consideration the assembly possibility of the devices to form a portable microplant in future. The illustration in Figure 3 shows a combination of 100 units of $\mu$ MIRHE which contains 1000 micro reactors and 1100 micro heat exchangers could be conceived. Although clearly not achieved in this work, the illustration in Figure 3 clearly shows the possibility of future potential for numberingup the devices presented in this work. 

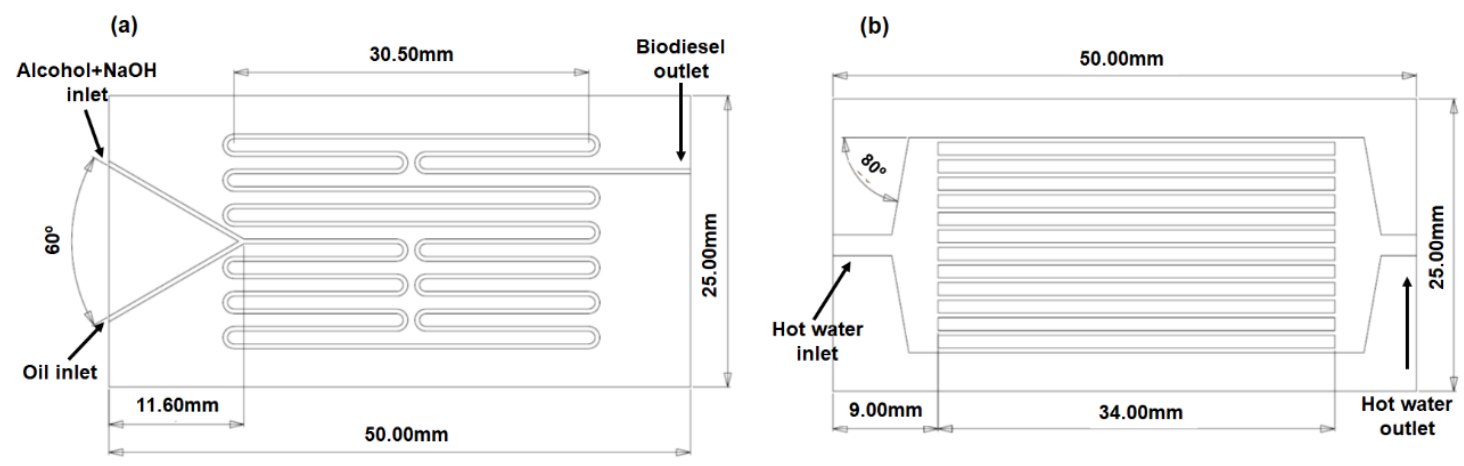

Figure 2. Schematic views (a) of the micro reactors layer and (b) of the micro heat exchanger layer.

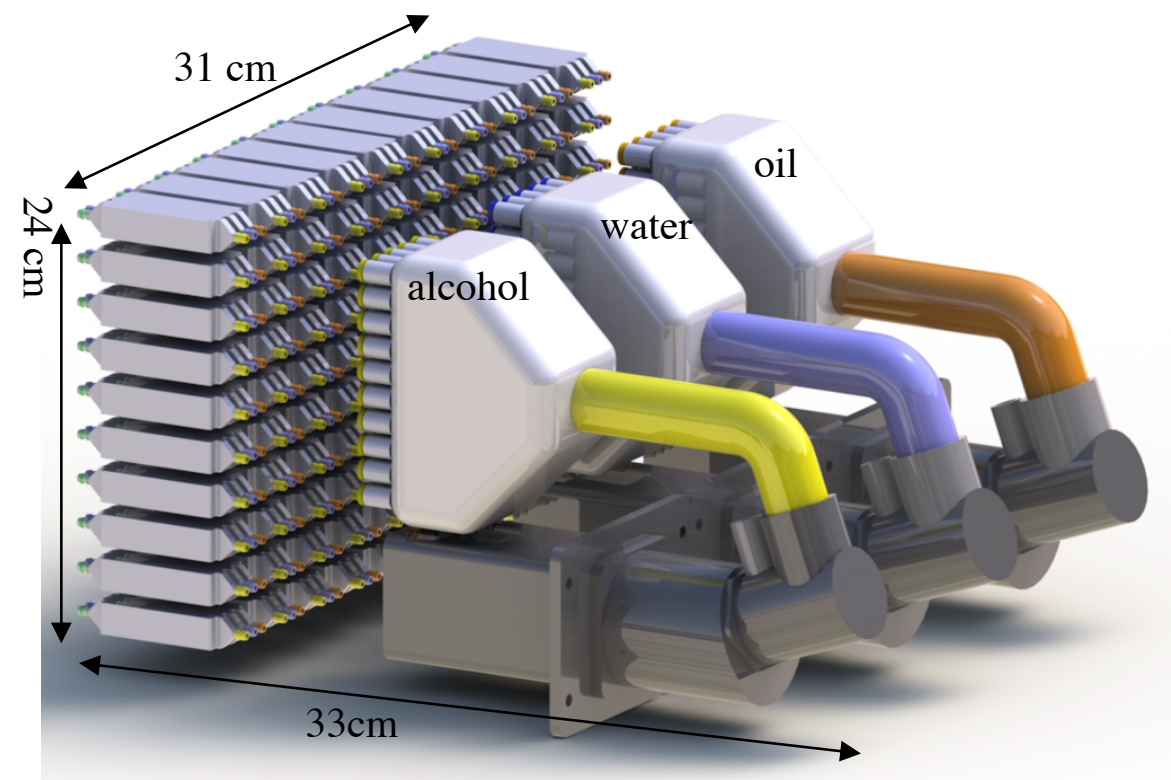

Figure 3. Illustrative drawing for a possible assembly, for the scaling up production of biodiesel, comprising 100 units of $\mu$ MIRHE (1000 micro reactors and 1100 micro heat exchangers).

\subsection{Microfabrication and Characterization of the $\mu \mathrm{MIRHE}$}

The $\mu$ MIRHE was fabricated in collaboration with the Three-Dimensional Technologies Division of the Renato Archer Information Technology Center $\mathrm{CTI} / \mathrm{Campinas} / \mathrm{SP}$, using the Mlab Cusing-R that is an additive manufacturing equipment 
that operates with the Selective Laser Melting (SLM) technique and utilizes an Ytterbium fiber laser of 100 Watt to selectively melt successive metallic powder layers. Figure 4 shows the final $\mu \mathrm{MIRHE}$ fabricated in Chromium-Cobalt alloy, where the chemical composition in mass is: $\mathrm{Co}(60,5 \%), \mathrm{Cr}(28 \%), \mathrm{W}(9 \%), \mathrm{Si}(1,5 \%)$, other elements $<1 \%$ : $\mathrm{Mn}, \mathrm{N}, \mathrm{Nb}, \mathrm{Fe}$, and it is free from nickel, beryllium and gallium. The final $\mu \mathrm{MIRHE}$ fabricated weighs only $123 \mathrm{~g}$ and occupies a volume of $15.875 \mathrm{~cm}^{3}$.

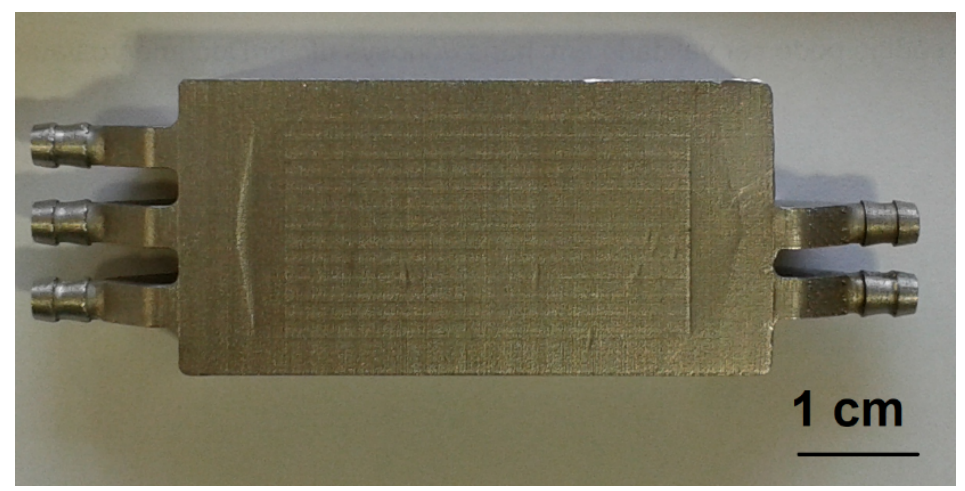

Figure 4. Photo of the $\mu$ MIRHE manufactured in Chromium-Cobalt utilizing the SLM additive manufacturing technique (weighs only $123 \mathrm{~g}$ )

A non-destructive characterization of the $\mu$ MIRHE was performed in collaboration with the Digital Image Processing Laboratory /PUC-Rio utilizing a Zeiss X-ray microtomograph model Xradia Versa 510 model. The imaging procedure allowed the device to be imaged in the three directions under a $360^{\circ}$ rotation, and the spatial resolution obtained was $25 \mu \mathrm{m}$.

Figure 5a shows four planes corresponding to four different positions of the device in which the microtomographic images were taken. Figure $5 \mathrm{~b}$ shows the four planes in the illustrative drawing of the interior of the channels, region that will be occupied by the fluids (in blue the hot water circuit, and in yellow the biodiesel reactants region). Figures 5c-f compare these microtomographic images with their respective CAD digital images. 
Figures $5 \mathrm{c}, 5 \mathrm{~d}, 5 \mathrm{e}$ and $5 \mathrm{f}$ correspond respectively to the following structures: 3 input connections (plane 1); plenums (plane 2); access channels of both the micro reactors and the micro heat exchangers (plane 3); and finally, the microchannels of both the micro reactors and the micro heat exchangers (plane 4). Each column of CAD images in Figure $5 f$ presents 21 dots in the segmented lines that corresponds to the sum of microchannels present in the cross section of 10 micro reactors and 11 micro heat exchangers.

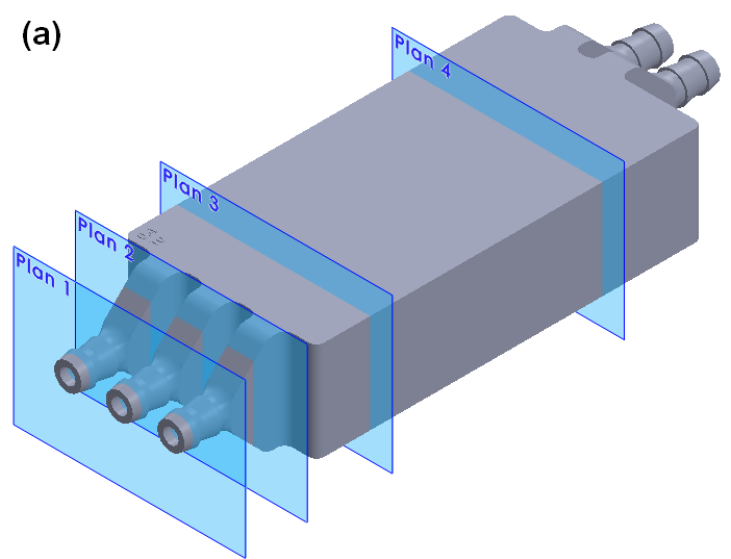

(c)

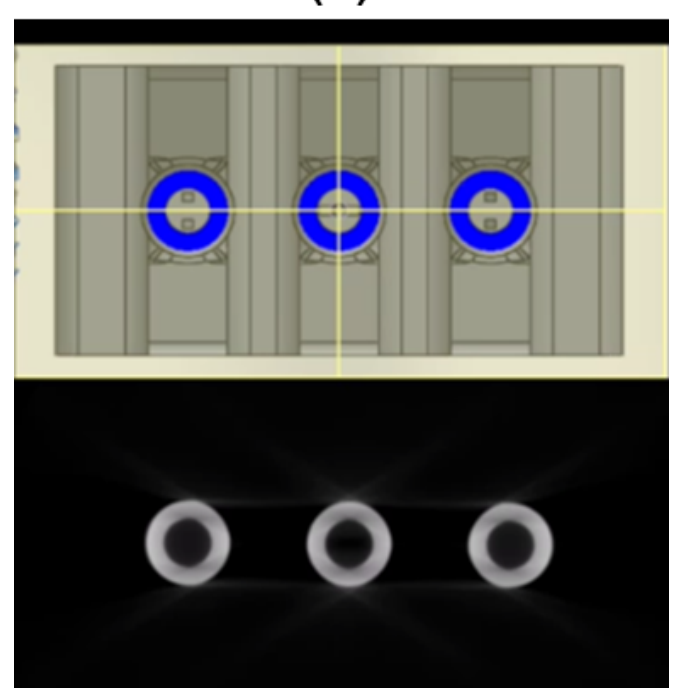

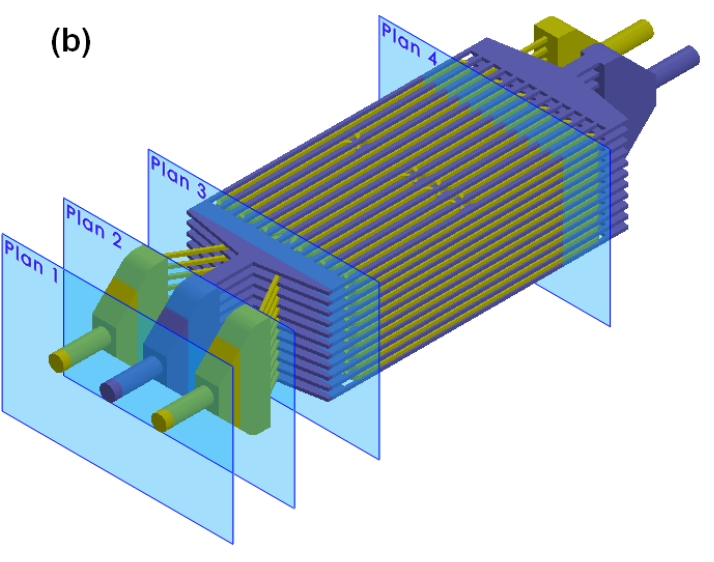

(d)

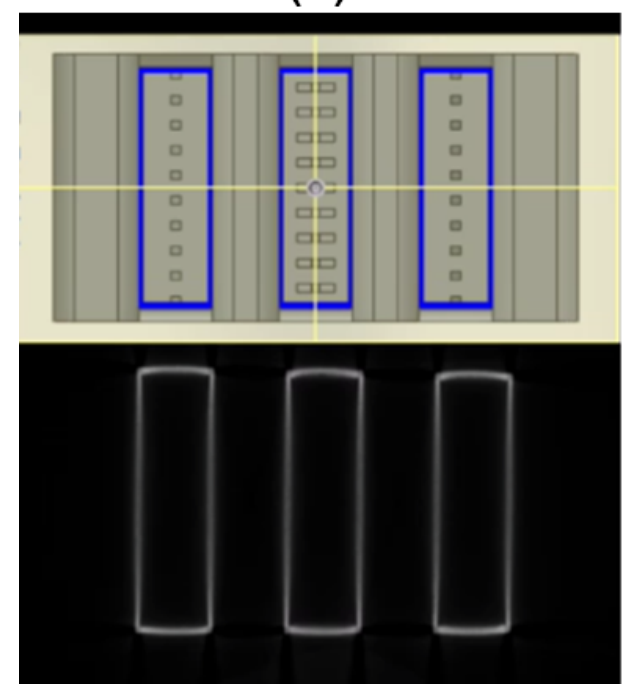


(e)

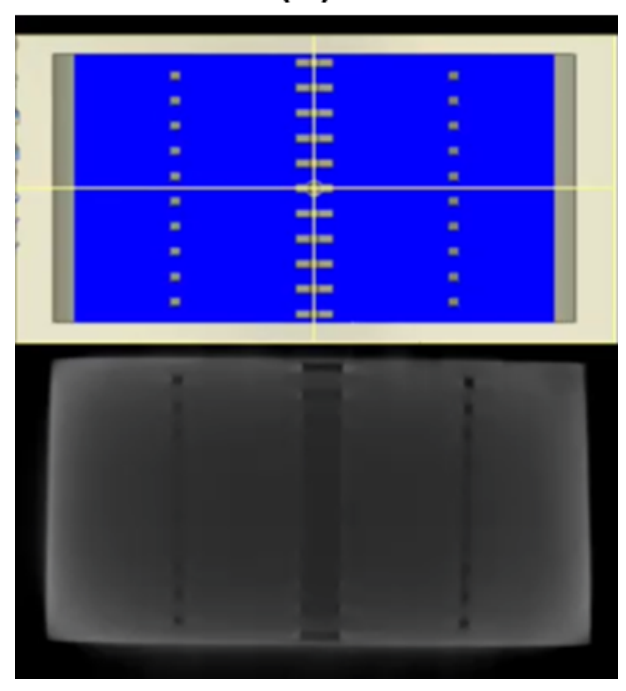

(f)

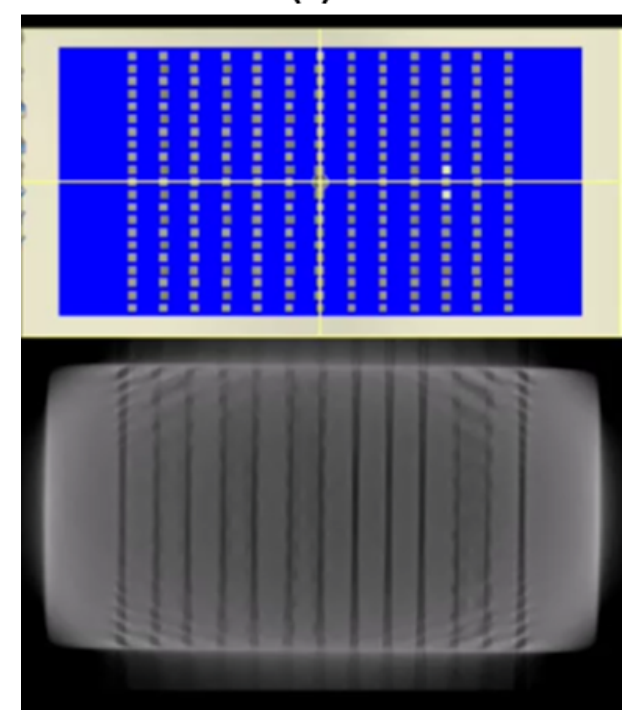

Figure 5. Detailed geometry of the $\mu \mathrm{MIRHE}$ in different plans. (a) CAD drawing showing the imaging planes; (b) CAD drawing showing the imaging planes in the detailed internal structure region that will be occupied by the fluids; Design CAD drawing (top) and microtomographic images (bottom) for: (c) plane 1; (d) plane 2; (e) plane 3 and (f) plane 4.

The manufacturing quality of $\mu \mathrm{MIRHE}$ was also verified by cutting the device along plane 4 . Figures $6 \mathrm{a}$ and $6 \mathrm{~b}$ show the resulting cross-section image obtained by optical microscopy. The mean width of the microchannel was $378.2 \mu \mathrm{m} \pm 0.3 \mu \mathrm{m}$, and the mean height of the microchannel was $396.6 \mu \mathrm{m} \pm 0.1 \mu \mathrm{m}$. These values are slightly smaller than that of $400 \mu \mathrm{m}$ set to the sides of the square cross section of the digital model. 
(a)

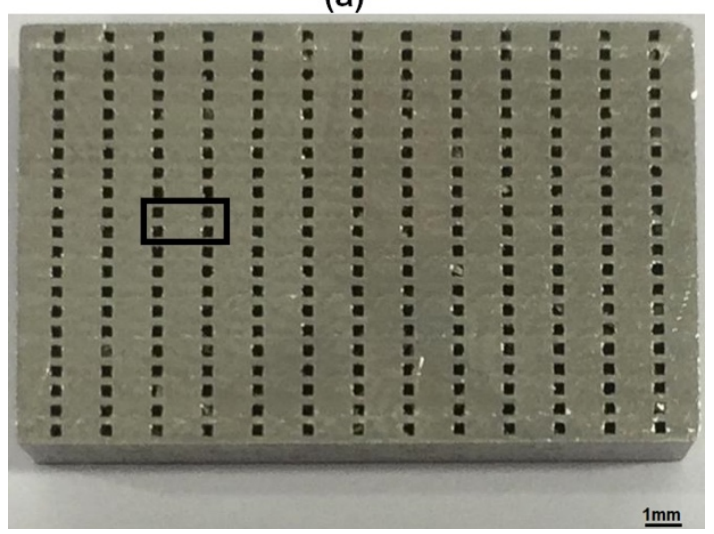

(b)

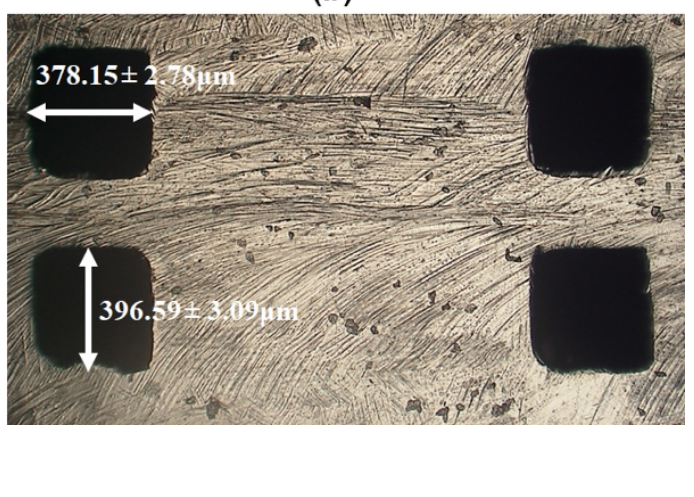

Figure 6. Optical image of the (a) cross section of the $\mu$ MIRHE; (b) dimensions of the cross sections of the channels

\section{Materials and experimental setup}

In the ethylic transesterification based synthesis of biodiesel studies in this work, triglycerides, i.e. the main components of vegetable oils, react with alcohol (in this case ethanol) to produce mono-alkyl ester (biodiesel) and glycerol. The transesterification is a reversible reaction that occurs in three consecutive steps. In the first step diglyceride is obtained from the reaction of alcohol with the triglycerides. In the second step, monoglycerides are produced from the reaction of alcohol with the diglycerides and, in the last step, glycerol is obtained from the reaction of alcohol with the monoglycerides. In each step, the fatty acid esters (biodiesel) are obtained. Figure 7 shows the stoichiometric representation of the three steps in transesterification reaction, where $\mathrm{k}_{1}$ to $\mathrm{k}_{6}$ represents the kinetic constants.

$$
\begin{aligned}
& \text { Triglyceride + Alcohol } \underset{k_{2}}{\stackrel{k_{1}}{\rightleftarrows}} \text { Diglyceride + Ester } \\
& \text { Diglyceride + Alcohol } \underset{k_{4}}{\stackrel{k_{3}}{\rightleftarrows}} \text { Monoglyceride + Ester } \\
& \text { Monoglyceride + Alcohol } \underset{k_{6}}{\stackrel{k_{5}}{\rightleftarrows}} \text { Glycerol + Ester }
\end{aligned}
$$


Figure 7. Scheme of the three consecutive steps of the transesterification reaction.

\subsection{Materials}

The reactants are food grade soybean vegetable oil with less than $0.3 \%$ acidity, bought in a local market, and absolute ethanol (99 GL) purchased from B'Herzog. The homogeneous basic catalyst used was sodium hydroxide $(\mathrm{NaOH})$ purchased from Petroquimios.

\subsection{Experimental setup and procedure}

The schematic design of the experimental setup for the production of biodiesel is shown in Figure 8. The main components of the experimental setup are: the $\mu$ MIRHE; two syringe pumps (model NE 1000 - New Era Pump Systems Inc.); a vessel to collect the final product of the transesterification reaction immersed in a water-ice bath; a reservoir providing the water for the reaction heating; a progressive cavity helical pump (Pumps NEMO - model NM003BY11S12B - NETZSCH) to deliver water from the tank through the heating system into the $\mu \mathrm{MIRHE}$. The heating system consisted of an auxiliary heat exchanger and an electric heater connected to a simple source of direct current (model PS-6100 of the ICEL), a data acquisition system (Agilent 34970-A) for thermocouples, a computer for data acquisition and processing. Eight thermocouples were used: (a) four thermocouples measured the external temperature of the $\mu \mathrm{MIRHE}$; (b) one was placed at the exit port to measure the temperature of the final reaction product; (c) two thermocouples measured the water temperature - one located at the entrance and the other one on the outlet of the micro heat exchangers and (d) one thermocouple measured the ambient temperature. 


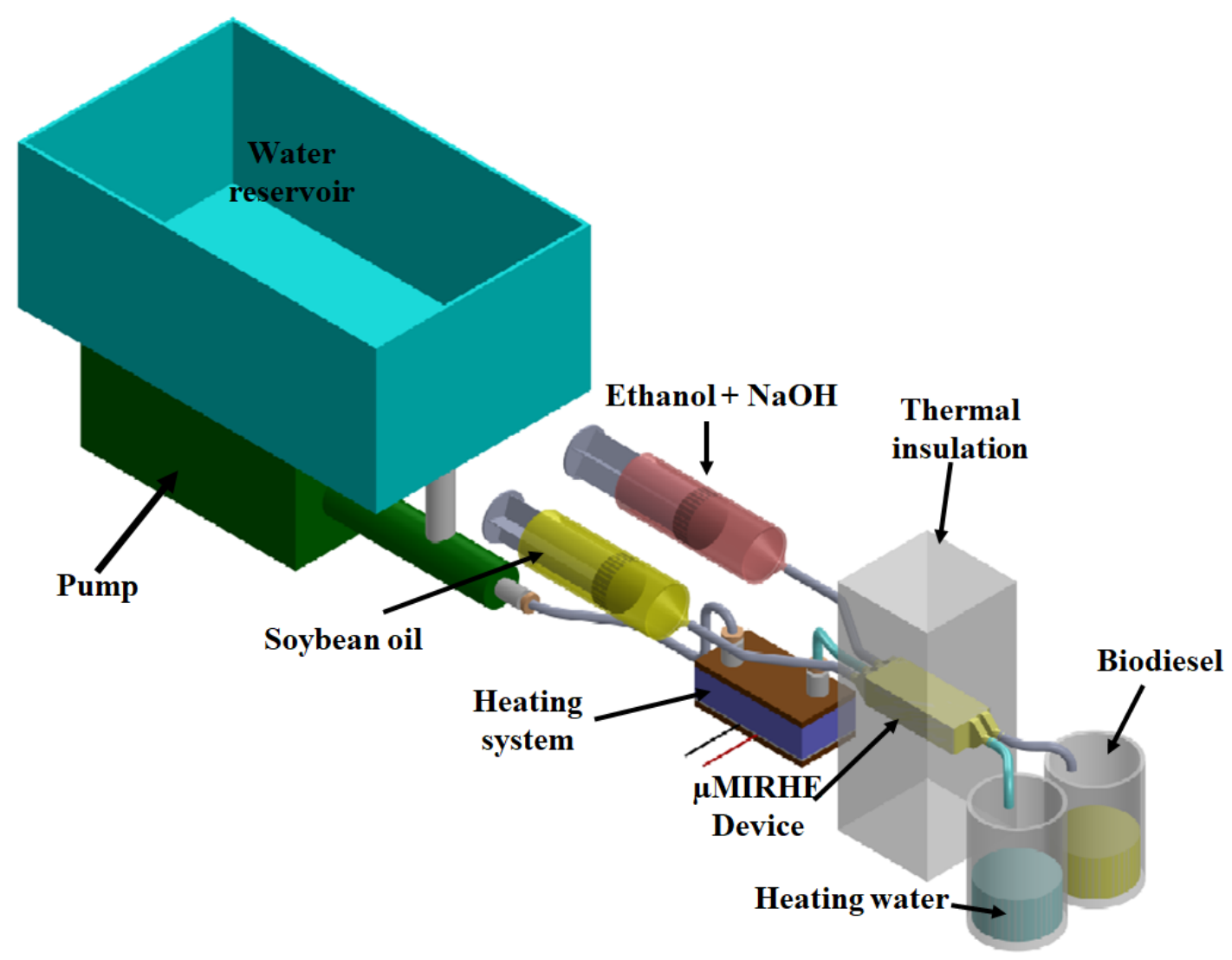

Figure 8. Schematic view of the experimental setup used in the synthesis of biodiesel

The experimental procedure for the production of biodiesel begins with the preparation of the solution of ethanol with the catalyst $\mathrm{NaOH}$. Then this solution and the soybean oils are independently injected in the micro reactors by using syringe with controlled flows. The distilled water on the other hand is pumped by the helicoidal pump to the auxiliary electrical heater simulating the waste heat recovery from an external thermal source. This water stream flow controls the reaction temperature in the $\mu \mathrm{MIRHE}$.

The product of the transesterification reaction is collected in a vessel immersed in a water and ice bath, which stops the transesterification reaction. The collected product is taken to a separation funnel, to separate the two phases. The bottom phase contains the biodiesel and the top phase contains the glycerol. Then the biodiesel is collected and 
washed with distilled water at a temperature of $75^{\circ} \mathrm{C}$ to remove the residues of catalyst, ethanol and glycerol. Finally, the biodiesel is dried in an oven at a temperature above $100^{\circ} \mathrm{C}$.

\subsection{Biodiesel Analysis}

The biodiesel was analyzed in a gas chromatography (Shimadzu - model 2010) according to the Brazilian norm technical ABNT NBR 15764, that which is based on the European technical norm EN14103, using a fused silica capillary column of dimensions $30 \mathrm{~m} \times 0.32 \mathrm{~mm} \times 0.25 \mu \mathrm{m}$, stationary phase of $95 \%$ dimethylpolysiloxane and $5 \%$ methylpolysiloxane and a flame ionization detector (FID). Helium gas was used as the drag gas and the ethyl heptadecanoate standard (Sigma-Aldrich) was used as the internal standard. The percentage of biodiesel yield in $(\% \mathrm{~m} / \mathrm{m})$ was calculated according to ABNT NBR 15764.

\subsection{Methodology}

Experiments were carried out to assess the influence of reaction temperature and residence time on the efficiency of biodiesel production in the $\mu$ MIRHE device. All experiments were conducted at molar ratio of 20/1 (ethanol/oil) and at catalyst concentration of $1.5 \mathrm{wt} \%$ (based on the oil mass). These reaction parameters were replicated from the work of Costa Junior55 who performed the synthesis of biodiesel in a device containing a single micro reactor. In this condition a promising ethyl ester yield was achieved: $92.6 \%$ for a residence time of 46.5 seconds.

The experiments were divided into three groups which are shown in Table 1, in order to investigate the biodiesel yield regarding: 1) reaction temperature for a fixed residence 
time, 2) effect of reducing residence time (in the range of 8min-1min) for a fixed heater voltage 3) effecting of reducing residence time (in a range smaller than $1 \mathrm{~min}$ ) for a fixed heater voltage.

In the first group (cases 1.1 to 1.3 ) the effect of the reaction temperature on biodiesel synthesis was analyzed for a fixed residence time of 3.88 minutes. In the second one (cases 2.1 to 2.6 ) the residence time was varied in the range of 1.55 to 7.76 minutes, keeping the reagents average temperature at the outlet of the $\mu$ MIRHE device at $45.0 \pm$ $0.1^{\circ} \mathrm{C}$. Finally, in the third group (cases 3.1 to 3.4 ), the residence time was varied and tested at the following values: $0.33 \mathrm{~min}, 0.39 \mathrm{~min}, 0.58 \mathrm{~min}$ and $0.78 \mathrm{~min}$.

As it would be very difficult to measure the reaction temperatures with sensors located inside the device, only external surface temperatures and outlet temperature were measured.

The residence time of the reaction indicates an average value of the time in which the reagent fluids are subjected to the diffusive-advective and reactive effects along the micro reactor. In the analysis of residence time it was assumed that the reactive effects occur predominantly in the triglyceride phase (oil phase), the residence time can be calculated taking into account only the volume of the layer of this phase in the micro reactor. Thus, residence time will be defined by the ratio of the volume of the triglyceride layer in the device to the volumetric flow rate of the triglyceride species. ${ }^{25}$

$$
R T=\frac{V_{T G}}{Q_{T G}}=\frac{L W H_{T G}}{Q_{T G}}
$$


Where, $R T$ represents the residence time; $Q_{T G}$ the triglyceride specie volumetric flow rate; $V_{T G}$ the volume of oil within the micro reactor; $H_{T G}$ is the height of the triglyceride layer; $W$ is microchannel width and $L$ is the microchannel length.

HTG is calculated based on the hypothesis that there is a stratified flow pattern in between the two immiscible reactants (oil and alcohol). Although the reaction usually occurs with a molar excess of alcohol in relation to oil, it is expected that the micro reactor is occupied mainly by the oil phase due to its higher molar mass when compared to the alcohol. Using the ratio between the two volumetric flow rates, QA/QTG, an implicit equation appears allowing the calculation of the HTG (see Pontes et al. ${ }^{56}$ for details). To determine the hydrodynamic parameters the following sequence of steps was adopted:

1 - Set an inlet molar ratio for alcohol to oil species;

2 - Calculate the ratio for volumetric flow rate through equation (2a);

3 - Determine the interface position through the equation $(2 b)$;

4 - Set a target residence time;

5 - Calculate the volumetric flow for the oil (TG) by equation (1);

6 - Calculate the volumetric flow for the alcohol (A) taking into account the results from step 2;

7 - Determine $\Delta \mathrm{P}$ from the expression for volumetric flow rate for the oil (TG) or the alcohol (A);

The ratio between QA and QTG can be related to the molar ratio of the reagents according the equation (2a) and/or through the volumetric flow ratio, equation (2b).

$$
\frac{\mathrm{Q}_{\mathrm{A}}}{\mathrm{Q}_{\mathrm{TG}}}=\left(\frac{\rho_{\mathrm{TG}} \mathrm{M}_{\mathrm{A}}}{\rho_{\mathrm{A}} \mathrm{M}_{\mathrm{TG}}}\right) \frac{\dot{\eta}_{\mathrm{A}}}{\dot{\eta}_{\mathrm{TG}}}
$$




$$
\frac{\mathrm{Q}_{\mathrm{A}}}{\mathrm{Q}_{\mathrm{TG}}}=\frac{\int_{0}^{\mathrm{W}} \int_{\mathrm{H}_{\mathrm{TG}}}^{\mathrm{H}} \mathrm{u}_{\mathrm{A}}(\mathrm{y}, \mathrm{z}) \mathrm{dydz}}{\int_{0}^{\mathrm{W}} \int_{0}^{\mathrm{H}_{\mathrm{TG}}} \mathrm{u}_{\mathrm{TG}}(\mathrm{y}, \mathrm{z}) \mathrm{dydz}}
$$

Where, $\rho, \mathrm{M}$ and $\dot{\eta}$ are the density, molar mass and molar flow for the respective species (oil, $T G$, and alcohol, $A$ ), and where $\mathrm{u}_{\mathrm{A}}(\mathrm{y}, \mathrm{z})$ and $\mathrm{u}_{\mathrm{TG}}(\mathrm{y}, \mathrm{z})$ are the velocity fields for alcohol and oil phase, written as:

$$
\begin{aligned}
& u_{\mathrm{A}}(y, z)=\sum_{i=1}^{\infty}\left(\frac{2}{w}\right)^{1 / 2} \operatorname{sen}\left(\frac{i \pi}{w} z\right) S_{i}\left\{\left(1+\frac{\mu_{T G}}{\mu_{A}}\right)\left[-\operatorname{senh}\left(\frac{H i \pi}{w}\right)+\operatorname{senh}\left(\frac{i \pi y}{w}\right)\right]+\right. \\
& +\left(1-\frac{\mu_{T G}}{\mu_{A}}\right)\left[\operatorname{senh}\left(\frac{\left(H-2 H_{T G}\right) i \pi}{w}\right)+\operatorname{senh}\left(\frac{i \pi\left(2 H_{T G}-y\right)}{w}\right)+\right. \\
& \left.\left.-\operatorname{senh}\left(\frac{i \pi\left(H-H_{T G}-y\right)}{w}\right)-\operatorname{senh}\left(\frac{i \pi\left(H+H_{T G}-y\right)}{w}\right)\right]+2 \operatorname{senh}\left(\frac{i \pi(H-y)}{w}\right)\right\} \\
& u_{T G}(y, z)=\sum_{i=1}^{\infty}\left(\frac{2}{w}\right)^{1 / 2} \operatorname{sen}\left(\frac{i \pi}{w} z\right) S_{i}\left\{\left(1+\frac{\mu_{A}}{\mu_{T G}}\right)\left[-\operatorname{senh}\left(\frac{H i \pi}{w}\right)+\operatorname{senh}\left(\frac{i \pi(H-y)}{w}\right)\right]+\right. \\
& +\left(\frac{\mu_{A}}{\mu_{T G}}-1\right)\left[\operatorname{senh}\left(\frac{\left(H-2 H_{T G}\right) i \pi}{w}\right)+\operatorname{senh}\left(\frac{i \pi\left(H-H_{T G}+y\right)}{w}\right)+\right. \\
& \left.\left.-\operatorname{senh}\left(\frac{i \pi\left(H-H_{T G}-y\right)}{w}\right)-\operatorname{senh}\left(\frac{i \pi\left(H-2 H_{T G}+y\right)}{w}\right)\right]+2 \operatorname{senh}\left(\frac{i \pi y}{w}\right)\right\}
\end{aligned}
$$

where $S_{\mathrm{i}}$ is given by

$$
S_{i}=\frac{-2 \sqrt{2} w^{5 / 2} \Delta P}{i^{3} L \pi^{3}\left[\left(\mu_{T G}-\mu_{A}\right) \operatorname{senh}\left(\frac{\left(H-2 H_{T G}\right) i \pi}{w}\right)+\left(\mu_{T G}+\mu_{A}\right) \operatorname{senh}\left(\frac{H i \pi}{w}\right)\right]}
$$

with $i=1,3,5, \ldots$

Table 1. Three Groups of all tested cases for biodiesel production considering a molar ratio of 20/1 (ethanol/oil) and catalyst concentration of $1.5 \mathrm{wt} \%$

\begin{tabular}{lllll}
\hline Cases & $\begin{array}{l}\text { Residence } \\
\text { time }\end{array}$ & $\begin{array}{l}\text { Ethanol+NaOH } \\
\text { flow rate }(\mathbf{m L} / \mathbf{h})\end{array}$ & $\begin{array}{l}\text { Oil flow rate } \\
(\mathbf{m L} / \mathbf{h})\end{array}$ & $\begin{array}{l}\text { Outlet Reaction } \\
\text { Temperature }\end{array}$ \\
\hline $\mathbf{1 . 1}$ & $3.88 \mathrm{~min}$ & $7.2 \pm 0.1$ & $8.3 \pm 0.1$ & $48.6 \pm 0.2^{\circ} \mathrm{C}$ \\
$\mathbf{1 . 2}$ & $3.88 \mathrm{~min}$ & $7.2 \pm 0.1$ & $8.3 \pm 0.1$ & $51.1 \pm 0.3^{\circ} \mathrm{C}$
\end{tabular}




\begin{tabular}{lllll}
$\mathbf{1 . 3}$ & $3.88 \mathrm{~min}$ & $7.2 \pm 0.1$ & $8.3 \pm 0.1$ & $59.1 \pm 0.1^{\circ} \mathrm{C}$ \\
\hline $\mathbf{2 . 1}$ & $1.55 \mathrm{~min}$ & $18.0 \pm 0.2$ & $20.8 \pm 0.2$ & $48.7 \pm 0.2^{\circ} \mathrm{C}$ \\
$\mathbf{2 . 2}$ & $2.33 \mathrm{~min}$ & $12.0 \pm 0.1$ & $13.8 \pm 0.1$ & $47.6 \pm 0.5^{\circ} \mathrm{C}$ \\
$\mathbf{2 . 3}$ & $3.10 \mathrm{~min}$ & $9.0 \pm 0.1$ & $10.4 \pm 0.1$ & $46.8 \pm 0.3^{\circ} \mathrm{C}$ \\
$\mathbf{2 . 4}$ & $3.88 \mathrm{~min}$ & $7.2 \pm 0.1$ & $8.3 \pm 0.1$ & $48.6 \pm 0.2^{\circ} \mathrm{C}$ \\
$\mathbf{2 . 5}$ & $6.21 \mathrm{~min}$ & $4.5 \pm 0.1$ & $5.2 \pm 0.1$ & $47.3 \pm 0.3^{\circ} \mathrm{C}$ \\
$\mathbf{2 . 6}$ & $7.76 \mathrm{~min}$ & $3.6 \pm 0.1$ & $4.1 \pm 0.1$ & $44.9 \pm 0.3^{\circ} \mathrm{C}$ \\
\hline $\mathbf{3 . 1}$ & $0.33 \mathrm{~min}$ & $108.0 \pm 1.1$ & $99.7 \pm 0.1$ & $50.8 \pm 0.2^{\circ} \mathrm{C}$ \\
$\mathbf{3 . 2}$ & $0.39 \mathrm{~min}$ & $72.0 \pm 0.7$ & $83.0 \pm 0.8$ & $52.8 \pm 0.2^{\circ} \mathrm{C}$ \\
$\mathbf{3 . 3}$ & $0.58 \mathrm{~min}$ & $60.0 \pm 0.6$ & $55.4 \pm 0.5$ & $51.2 \pm 0.3^{\circ} \mathrm{C}$ \\
$\mathbf{3 . 4}$ & $0.78 \mathrm{~min}$ & $36.0 \pm 0.4$ & $41.5 \pm 0.4$ & $43.8 \pm 0.1^{\circ} \mathrm{C}$ \\
\hline
\end{tabular}

As mention before, in the $\mu$ MIRHE the reaction temperature (i.e. the external surface temperatures and outlet temperature) is controlled by the water passing through the microchannels of the micro heat exchange layers which by its turn is controlled by the voltage set in the electrical heater. So, Table 2 present the following parameters for all the tested cases: voltage set in the electrical heater, water temperatures at the inlet and the outlet of the $\mu \mathrm{MIRHE}$, temperatures at the external surface of the $\mu \mathrm{MIRHE}$ device. The flow rate of the water was $14.5 \pm 0.2 \mathrm{ml} / \mathrm{min}$.

Table 2. Water temperatures of all performed cases for biodiesel production

\begin{tabular}{lllll}
\hline Cases & $\begin{array}{l}\text { Voltage across } \\
\text { electrical resistance }\end{array}$ & $\begin{array}{l}\text { Water Inlet } \\
\text { Temp. }\end{array}$ & $\begin{array}{l}\text { Water Outlet } \\
\text { Temp. }\end{array}$ & $\begin{array}{l}\text { External } \boldsymbol{\mu M I R H E} \\
\text { Temperature }\end{array}$ \\
\hline $\mathbf{1 . 1}$ & $17.5 \pm 0.3 \mathrm{~V}$ & $63.0 \pm 0.3^{\circ} \mathrm{C}$ & $60.7 \pm 0.4{ }^{\circ} \mathrm{C}$ & $61.9 \pm 0.3^{\circ} \mathrm{C}$ \\
$\mathbf{1 . 2}$ & $20.0 \pm 0.3 \mathrm{~V}$ & $76.0 \pm 0.2{ }^{\circ} \mathrm{C}$ & $73.1 \pm 0.2{ }^{\circ} \mathrm{C}$ & $73.4 \pm 0.6{ }^{\circ} \mathrm{C}$ \\
$\mathbf{1 . 3}$ & $21.0 \pm 0.3 \mathrm{~V}$ & $80.2 \pm 0.7{ }^{\circ} \mathrm{C}$ & $77.5 \pm 0.4{ }^{\circ} \mathrm{C}$ & $79.4 \pm 1.1{ }^{\circ} \mathrm{C}$ \\
\hline $\mathbf{2 . 1}$ & $17.5 \pm 0.3 \mathrm{~V}$ & $65.4 \pm 0.3{ }^{\circ} \mathrm{C}$ & $61.6 \pm 0.6{ }^{\circ} \mathrm{C}$ & $62.0 \pm 0.1{ }^{\circ} \mathrm{C}$ \\
$\mathbf{2 . 2}$ & $17.5 \pm 0.3 \mathrm{~V}$ & $67.2 \pm 0.9{ }^{\circ} \mathrm{C}$ & $61.1 \pm 03{ }^{\circ} \mathrm{C}$ & $64.9 \pm 0.9{ }^{\circ} \mathrm{C}$ \\
$\mathbf{2 . 3}$ & $17.5 \pm 0.3 \mathrm{~V}$ & $67.6 \pm 0.3{ }^{\circ} \mathrm{C}$ & $62.4 \pm 0.3{ }^{\circ} \mathrm{C}$ & $65.0 \pm 0.5{ }^{\circ} \mathrm{C}$ \\
$\mathbf{2 . 4}$ & $17.5 \pm 0.3 \mathrm{~V}$ & $63.0 \pm 0.3{ }^{\circ} \mathrm{C}$ & $60.7 \pm 0.4{ }^{\circ} \mathrm{C}$ & $61.9 \pm 0.3{ }^{\circ} \mathrm{C}$ \\
$\mathbf{2 . 5}$ & $17.5 \pm 0.3 \mathrm{~V}$ & $68.8 \pm 0.5{ }^{\circ} \mathrm{C}$ & $61.5 \pm 0.8^{\circ} \mathrm{C}$ & $67.8 \pm 0.7{ }^{\circ} \mathrm{C}$ \\
$\mathbf{2 . 6}$ & $17.5 \pm 0.3 \mathrm{~V}$ & $70.9 \pm 0.6{ }^{\circ} \mathrm{C}$ & $62.1 \pm 0.6{ }^{\circ} \mathrm{C}$ & $68.4 \pm 0.6{ }^{\circ} \mathrm{C}$ \\
\hline $\mathbf{3 . 1}$ & $17.5 \pm 0.3 \mathrm{~V}$ & $68.7 \pm 0.3{ }^{\circ} \mathrm{C}$ & $61.7 \pm 0.5{ }^{\circ} \mathrm{C}$ & $66.2 \pm 0.1{ }^{\circ} \mathrm{C}$ \\
$\mathbf{3 . 2}$ & $17.5 \pm 0.3 \mathrm{~V}$ & $66.1 \pm 0.2{ }^{\circ} \mathrm{C}$ & $56.2 \pm 0.8{ }^{\circ} \mathrm{C}$ & $61.0 \pm 0.6{ }^{\circ} \mathrm{C}$ \\
$\mathbf{3 . 3}$ & $17.5 \pm 0.3 \mathrm{~V}$ & $68.6 \pm 0.2{ }^{\circ} \mathrm{C}$ & $59.8 \pm 0.2{ }^{\circ} \mathrm{C}$ & $64.4 \pm 0.4{ }^{\circ} \mathrm{C}$ \\
$\mathbf{3 . 4}$ & $17.5 \pm 0.3 \mathrm{~V}$ & $67.1 \pm 0.2{ }^{\circ} \mathrm{C}$ & $60.8 \pm 0.2{ }^{\circ} \mathrm{C}$ & $62.2 \pm 0.5{ }^{\circ} \mathrm{C}$ \\
\hline
\end{tabular}




\section{Results and Discussion}

We studied how the biodiesel yield is influenced by the reaction temperature (i.e. through the temperature measured at the outlet of the $\mu \mathrm{MIRHE}$ ) and residence time.

Firstly, by fixing the residence time, the biodiesel yield was measured as a function of reaction temperature - the yield increased from $89.8 \%$ to $97.6 \%$ (Table 3) by increasing the temperature. The average temperature of the reagents at the outlet of the $\mu$ MIRHE device was controlled not to exceed $65^{\circ} \mathrm{C}$, in order to avoid evaporation of the alcohol which could decrease the biodiesel production. The uncertainty in the biodiesel yield was around $4 \% \mathrm{~m} / \mathrm{m}$ for all studied case.

Table 3. Biodiesel yield at different temperatures (molar ratio of 20/1 (ethanol/oil), $1.5 \mathrm{wt} \%$ of catalyst concentration residence time: 3.88 minutes)

\begin{tabular}{llllc}
\hline Cases & $\begin{array}{l}\text { Residence } \\
\text { time }\end{array}$ & $\begin{array}{l}\text { External } \\
\boldsymbol{\mu M I R H E} \\
\text { Temperature }\end{array}$ & $\begin{array}{l}\text { Outlet } \\
\text { Reaction } \\
\text { Temperature }\end{array}$ & $\begin{array}{c}\text { Yield of } \\
\text { biodiesel } \\
(\boldsymbol{\%} \mathbf{m} / \mathbf{m})\end{array}$ \\
\hline $\mathbf{1 . 1}$ & $3.88 \mathrm{~min}$ & $61.9 \pm 0.3^{\circ} \mathrm{C}$ & $48.6 \pm 0.2^{\circ} \mathrm{C}$ & 89.8 \\
$\mathbf{1 . 2}$ & $3.88 \mathrm{~min}$ & $73.4 \pm 0.6^{\circ} \mathrm{C}$ & $51.1 \pm 0.3{ }^{\circ} \mathrm{C}$ & 93.3 \\
$\mathbf{1 . 3}$ & $3.88 \mathrm{~min}$ & $79.4 \pm 1.1^{\circ} \mathrm{C}$ & $59.1 \pm 0.1^{\circ} \mathrm{C}$ & 97.6 \\
\hline
\end{tabular}

Next we examined the role of reaction time (residence time). The first set of tests were performed by maintaining the heater voltage at $17.5 \mathrm{~V}$. The measurement of the real reaction temperature inside the channel is instrumentally difficult to be obtained due to the high number of layers and channels and also due to the size of them. Addionally is expected that the real reaction temperature might vary along the channel. Based on these two factors both measured temperatures, the external and the outlet reaction ones, will be presented. The reaction temperature would be expected, at some point, to be in between this two measured ones. For practical purposes we will take the outlet reaction 
temperature as an indicator of the reaction temperature for comparison purpose in between cases. Figure 9 presents the external $\mu$ MIRHE temperature that refers to the average measured temperature at the top and bottom external surface of the $\mu \mathrm{MIRHE}$ and the measured temperature at the outlet reactants branch, over the residence time. Figure 10 plots the variation of yield of the ethyl esters (biodiesel) against the residence time. Despite the low statistical variance presented by the outlet reaction temperatures (below $2{ }^{\circ} \mathrm{C}$ ), the reaction temperature influence can still be noticed on the yield of ethyl esters (see Table 4). Clearly, although a higher yield of biodiesel is expected for a longer residence time (case 2.6), in this case the outlet reaction temperature is the lowest, thus, despite the high yield of biodiesel of $94 \%$ (as an expected consequence of the high residence time) this is not the largest yield among the analyzed cases. Similarly, a high ethyl esters yield would be expected for the highest outlet reaction temperature (case 2.1). However, as this case has the shortest residence time, the yield, despite being high (95.6\%), due to the high reaction temperature, is not the highest among the analyzed cases. In fact, the best combination of residence time and reaction temperature is observed for case 2.4 which showed a $97.3 \%$ yield. None the less, a high yield of biodiesel (above $90 \% \mathrm{~m} / \mathrm{m}$ ) for almost all the analyzed cases confirmes the excellent efficiency and performance of the $\mu \mathrm{MIRHE}$ device presented, even for a significant variations in both the residence time and/or the outlet reaction temperature. The uncertainty in the biodiesel yield was around $4 \% \mathrm{~m} / \mathrm{m}$ for all studied case.

Table 4. Yield of ethyl esters relative to the residence time for the $\mu$ MIRHE device using an ethanol/oil molar ratio of 20/1, a catalyst concentration of $1.5 \mathrm{wt} \%$ and a fixed electric voltage of $17.5 \mathrm{~V}$ (aiming an outlet reaction temperature of $45^{\circ} \mathrm{C}$ ). 


\begin{tabular}{llllc}
\hline Cases & $\begin{array}{l}\text { Residence } \\
\text { time }\end{array}$ & $\begin{array}{l}\text { External } \boldsymbol{\mu M I R H E} \\
\text { Temperature }\end{array}$ & $\begin{array}{l}\text { Outlet Reaction } \\
\text { Temperature }\end{array}$ & $\begin{array}{c}\text { Yield of biodiesel } \\
(\boldsymbol{\%} \mathbf{m} / \mathbf{m})\end{array}$ \\
\hline $\mathbf{2 . 1}$ & $1.55 \mathrm{~min}$ & $62.0 \pm 0.1^{\circ} \mathrm{C}$ & $48.7 \pm 0.2^{\circ} \mathrm{C}$ & 95.6 \\
$\mathbf{2 . 2}$ & $2.33 \mathrm{~min}$ & $64.9 \pm 0.9^{\circ} \mathrm{C}$ & $47.6 \pm 0.5^{\circ} \mathrm{C}$ & 96.1 \\
$\mathbf{2 . 3}$ & $3.10 \mathrm{~min}$ & $65.0 \pm 0.5^{\circ} \mathrm{C}$ & $46.8 \pm 0.3^{\circ} \mathrm{C}$ & 90.6 \\
$\mathbf{2 . 4}$ & $3.88 \mathrm{~min}$ & $61.9 \pm 0.3^{\circ} \mathrm{C}$ & $48.6 \pm 0.2^{\circ} \mathrm{C}$ & 97.3 \\
$\mathbf{2 . 5}$ & $6.21 \mathrm{~min}$ & $67.8 \pm 0.7^{\circ} \mathrm{C}$ & $47.3 \pm 0.3^{\circ} \mathrm{C}$ & 87.8 \\
$\mathbf{2 . 6}$ & $7.76 \mathrm{~min}$ & $68.4 \pm 0.6^{\circ} \mathrm{C}$ & $44.9 \pm 0.3^{\circ} \mathrm{C}$ & 94.0 \\
\hline
\end{tabular}

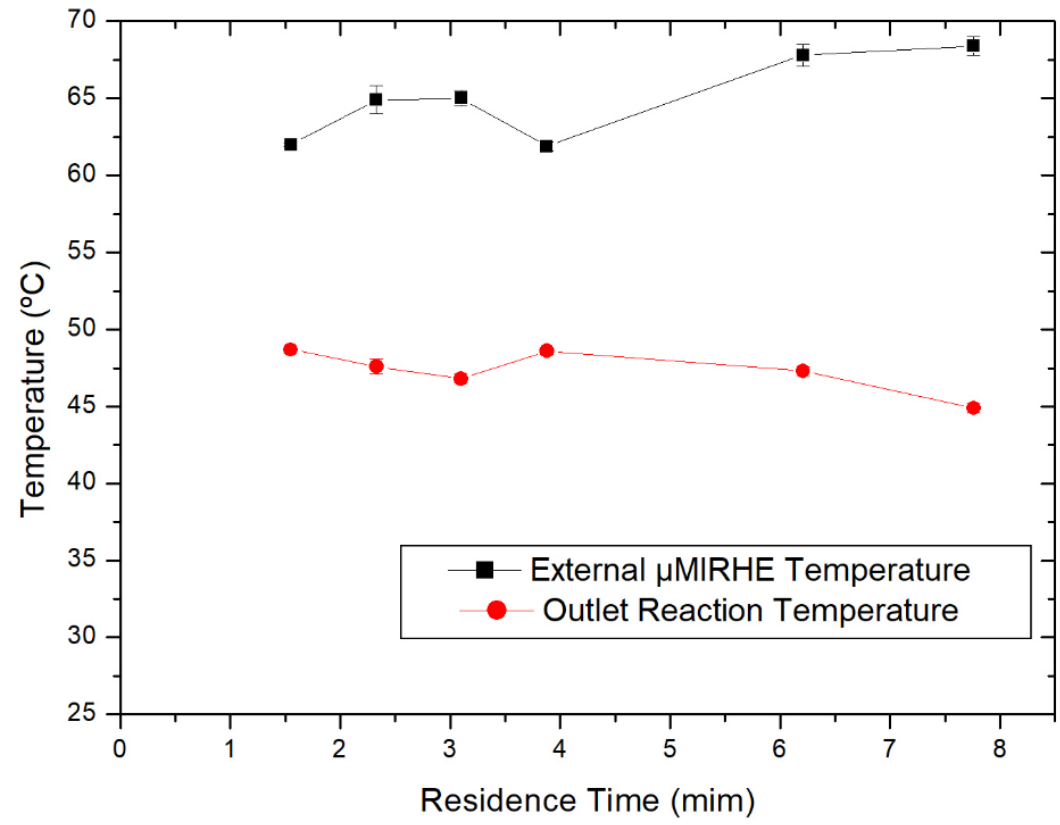

Figure 9. Profiles of the external $\mu \mathrm{MIRHE}$ temperature and outlet reaction temperature over residence time (cases 2.1 to 2.6 presented in Table 4). 


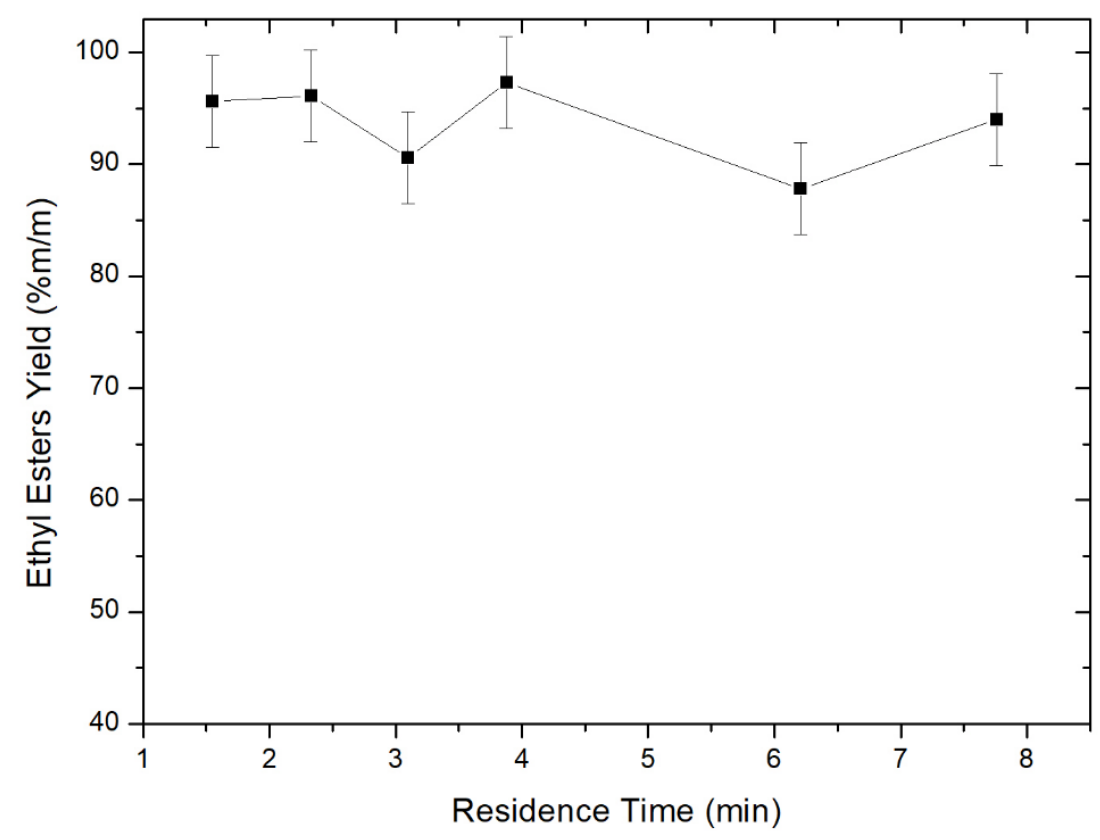

Figure 10. Profile of the yield of the ethyl esters (biodiesel) over residence time for the $\mu$ MIRHE device (cases 2.1 to 2.6 presented in Table 4).

Next, we examined the possibility of reducing the residence time by exploiting higher reaction temperature, in order to demonstrate the benefit of exploiting waste heating. The results are presented in Table 5. Clearly, significant variations of residence time, where the highest tested value $(0.78 \mathrm{~min})$ was a little more than twice the smallest value $(0.33$ min) caused a yield change of 10 points percentage but still the biodiesel production remained high. Particular attention should be payed to the case 3.3 where the highest biodiesel yield, a staggering value of $99.6 \% \mathrm{~m} / \mathrm{m}$, was achieved at a very low residence time of 0.58 minutes (34.8 seconds) at an outlet reaction temperature of $51.2{ }^{\circ} \mathrm{C}$. The present result is very promising. According to the established quality standards, such as those set by the American Society of Testing and Materials (ASTM), ASTM D6751, and the one established in the European Union through EN 14214 of the European Committee for Standardization (European Committee for Standardization - CEN), to be considered 
biodiesel, the minimum percentage of $96.5 \%$ in mass of ester is required in the reactants products .57 The closest result from additive manufacturing based micro-chemical plants come from a recent work by Lopes et al. ${ }^{46}$ who, using a polymeric $3 \mathrm{D}$ printed biodiesel chemical plant composed by four milli reactors, reported a $73.51 \%$ of biodiesel yield, with a residence time of 10 seconds.

Table 5. Yield of ethyl esters for residence times of less than 1 minute in the $\mu$ MIRHE device using a 20/1 ethanol/oil molar ratio and catalyst concentration of $1.5 \mathrm{wt} \%$.

\begin{tabular}{llllc}
\hline Cases & $\begin{array}{l}\text { Residence } \\
\text { time }\end{array}$ & $\begin{array}{l}\text { External } \\
\boldsymbol{\mu} \text { MIRHE } \\
\text { Temperature }\end{array}$ & $\begin{array}{l}\text { Outlet } \\
\text { Reaction } \\
\text { Temperature }\end{array}$ & $\begin{array}{c}\text { Yields of } \\
\text { biodiesel } \\
(\% \mathbf{m} / \mathbf{m})\end{array}$ \\
\hline $\mathbf{3 . 1}$ & $\begin{array}{l}0.33 \mathrm{~min} \\
(19.8 \mathrm{~s})\end{array}$ & $66.2 \pm 0.1{ }^{\circ} \mathrm{C}$ & $50.8 \pm 0.2^{\circ} \mathrm{C}$ & 92.9 \\
$\mathbf{3 . 2}$ & $\begin{array}{l}0.39 \mathrm{~min} \\
(23.4 \mathrm{~s})\end{array}$ & $61.0 \pm-0.6^{\circ} \mathrm{C}$ & $52.8 \pm 0.2^{\circ} \mathrm{C}$ & 88.3 \\
$\mathbf{3 . 3}$ & $\begin{array}{l}0.58 \mathrm{~min} \\
(34.8 \mathrm{~s})\end{array}$ & $64.4 \pm 0.4{ }^{\circ} \mathrm{C}$ & $51.2 \pm 0.3^{\circ} \mathrm{C}$ & 99.6 \\
$\mathbf{3 . 4}$ & $\begin{array}{l}0.78 \mathrm{~min} \\
(46.8 \mathrm{~s})\end{array}$ & $62.2 \pm 0.5{ }^{\circ} \mathrm{C}$ & $43.8 \pm 0.1{ }^{\circ} \mathrm{C}$ & 95.5 \\
\hline
\end{tabular}

To get a sense of potential impact of the results obtained, based the maximum biodiesel yield of $99.6 \%$ obtained with a residence time of around 35 seconds (case 3.3 in Table 5), the scale-up assembly proposed in Figure 3, comprising 100 units of $\mu$ MIRHE (with 1000 micro reactors and 1100 micro heat exchangers in total), should be able to produce 133 liters per day. This estimate, however, does not take in to account the potentially major challenges in the numbering-up process. For example, difficulties around uniform flow distribution into the individual $\mu \mathrm{MIRHE}$ units and also non-uniform performance and reaction efficiencies in different units. The performance of the whole microplant will be clearly susceptible to such challenges.46 However, the overall dimensions, compactness 
and light weight of the conceived device clearly indicates its potential for exploitation as a portable biodiesel production unit.

\section{Conclusions}

An innovative microfluidic device, named here as $\mu$ MIRHE, was built using additive manufacturing (also called 3D printing) The device design comprises layers of micro reactors and micro heat exchangers monolithically integrated in a layer-wise pattern in a metal body without using any assembly or fixing tools such as glue, screws, clamps, etc. which vastly simplifies the design and improves its durability. It weighs only $123 \mathrm{~g}$ and has 10 micro reactors intercalated with 11 micro heat exchangers both containing microchannels of $400 \mu \mathrm{m} \times 400 \mu \mathrm{m}$ square cross section. The lengths of these micro channels were $432.57 \mathrm{~mm}$ and $34 \mathrm{~mm}$ in all micro reactors and micro heat exchanger, respectively.

The design helped evaluate the potential of exploiting waste heat to produce biodiesel at various residence time and reaction temperatures. The device enabled a high rate of conversion, showing biodiesel yields of over $90 \%$ for almost all analyzed cases, reaching a maximum of $99.6 \%$ at temperature of $51.2^{\circ} \mathrm{C}$ and at residence time of only 0.58 minutes (only 34.8 second). The performance can be projected to an estimated biodiesel production of $1.33 \mathrm{~L} /$ day from a single $\mu \mathrm{MIRHE}$ device or $133 \mathrm{~L} /$ day using 100 units of $\mu \mathrm{MIRHE}$, thereby clearly offering the potential for exploitation as light weight, spacesaving and, as a result, a portable biodiesel production plant.

This work demonstrates the feasibility of exploiting $\mu$ MIRHE device to produce biodiesel via transesterification reaction based on ethyl alcohol. Such device represents a proof of concept relating the fabrication of complexes and efficient microfluidic devices utilizing SLM additive manufacturing technique. An important characteristic of $\mu$ MIRHE 
is the capability to be assembled to a great number of identical units increasing the production of biodiesel. This assembly might be competitive in terms of efficiency in biodiesel production compared to the traditional batch production method. Importantly it allows use in loco of otherwise wasted energy to intensify the reaction. Also, the device provides two important environmental benefits: firstly, by allowing energy reuse it raises the energy efficiency; Secondly, it allows high yield reaction obtained using ethyl rather than the toxic methyl alcohol as reactant. Methyl alcohol has environmentally adverse influence, therefore, for countries such as Brazil which produce huge amounts of this product, the proposed $\mu$ MIRHE has a holistic advantage.

\section{Acknowledgements}

The authors would like to acknowledge the partial financial support provided by the Brazilian agencies (CNPq, FAPERJ, and ANP PRH-37), to the Laboratory of Fuels and Petroleum Derivatives (LabCOM) of the School of Chemistry of UFRJ, the Digital Image Processing Laboratory of the Pontifical Catholic University of Rio de Janeiro - Puc-Rio, and TecnoHow for the support in additive manufacturing. CPNC would like to acknowledge the hospitality of the UCL Mechanical Engineering during the final preparation of the manuscript. 
7. References

(1) Dennis, B. H.; Jin, W.; Cho, J.; Timmons, R. B. Inverse determination of kinetic rate constants for transesterification of vegetable oils. Inverse Probl. Sci. En. 2008, $16(6), 693-704$.

(2) Leung, D. Y. C.; Wu, X.; Leung, M. K. H. A review on biodiesel production using catalyzed transesterification. Appl. Energ. 2010, 87, 1083-1095.

(3) Sun, P.; Wang, B.; Yao, J.; Zhang, L.; Xu, N. Fast Synthesis of Biodiesel at High Throughput in Microstructured Reactor". Ind. Eng. Chem. Res. 2010, 49, 12591264.

(4) Aransiola, E. F.; Ojumu, T. V.; Oyekola, O. O.; Madzimbamuto, T. F.; IkhuOmoregbe, D. I. O. A review of current technology for biodiesel production: State of the art. Biomass Bioenerg. 2014, 61, 276-297.

(5) Meher, L. C.; Sagar, D. V.; Naik, S. N. Technical aspects of biodiesel production by transesterificaton - a review. Renew. Sust. Energ. Rev. 2006, 10, 248-268.

(6) Xie, T.; Lixiong, Z.; Nanping, X. Biodiesel synthesis in microreactors. Green Process Synth. 2012, 1, 61-70.

(7) Sun, J.; Ju, J.; Ji, L.; Zhang, L.; Xu, N. Synthesis of Biodiesel in Capillary Microreactors. Ind. Eng. Chem. Res. 2008, 47, 1398-1403.

(8) Demirbas, A. Comparison of transesterification methods for production of biodiesel from vegetable oils and fats. Energ. Convers. Manage. 2008, 49, 125-130. 
(9) Charoenwat, R.; Dennis, B.H. Transesterification of Vegetable Oils with a Continous Flow Capillary Reactor. In Proceedings of the ASME Early Career Technical Conference. Arlington, TX, April 17-18, 2009.

(10) Wen, Z.; Yu, X.; Tu, S. T.; Yan, J.; Dahlquist, E. Intensification of biodiesel synthesis using zigzag microchannel reactors. Bioresour. Technol. 2009, 100, 30543060.

(11) Pengmei, L.; Yuan, Z.; Lianhua, L.; Zhongming, W.; Wen, L. Biodiesel from different oil using fixed-bed and plug-flow reactors. Renew Energy. 2010, 35, 283287.

(12) Falahati, H.; Tremblay, A. Y. The effect of flux and residence time in the production of biodiesel from various feedstocks using a membrane reactor. Fuel. 2012, $91(1), 126-133$.

(13) Rahimi, M.; Aghel B.; Alitabar, M.; Sepahvand, A.; Ghasempour, H. R. Optimization of biodiesel production from soybean oil in a microreactor. Energ. Convers. Manage. 2014, 79, 599-605.

(14) Dai, J. Y.; Li, D. Y.; Zhao, Y. C.; Xiu, Z. L. Statistical Optimization for Biodiesel Production from Soybean Oil in a Microchannel Reactor. Ind. Eng. Chem. Res. $\mathbf{2 0 1 4}, 53,9325-9330$

(15) Madhawan, A.; Arora, A.; Das, J.; Kuila, A.; Sharma, V. Microreactor technology for biodiesel production: a review. Biomass Convers. Bior. 2017, 8 (2), 485-496.

(16) Tiwari, A.; Rajesh, V. M.; Yadav S. Biodiesel production in micro-reactors: A review. Energy Sustain. Dev. 2018, 43, 143-161. 
(17) Santana, H. S.; Tortola, D. S.; Silva Jr, J. L; Taranto O. P. Development of microreactors applied on biodiesel synthesis: from experimental investigation to numerical approaches. J. Ind. Eng. Chem. 2019, 69, 1-12.

(18) Hessel, V.; Lowe, H.; Schonfeld, F. Micromixers - a review on passive and active mixing principles. Chem. Eng. Sci. 2005, 60, 2479-2501.

(19) Kobayashi, J.; Mori, Y.; Kobayashi, S. Multiphase organic synthesis in microchannel reactors. Chem. Asian J. 2006, 1, 22-35.

(20) Pohar, A.; Plazl, I. Process intensification through microreactor application. Chem Biochem Eng Q. 2009, 23 (4), 537-544.

(21) Kumar, D.; Kumar, G.; Poonam; Singh, C. P. Fast, Easy Ethanolysis of Coconut Oil for Biodiesel Production Assisted by Ultrasonication. Ultrason. Sonochem. 2010, $17,555-559$.

(22) Lee, C. Y.; Chang, C. L.; Wang, Y. N.; Fu, L. M. Microfluidic mixing: a review. Int. J. Mol.Sci. 2011, 12, 3263-3287.

(23) Salic, A.; Zelic, B. Microreactors - Portable factories for biodiesel fuel production. Goriva i Maziva. 2011, 50, 85-110.

(24) Costa Junior, J. M.; Naveira-Cotta, C. P. Estimation of Kinetic Constants in Micro-Reactors for Biodiesel Synthesis: Bayesian Inference with Reduced Mass Transfer Model. Chem. Eng. Res. Des. 2019, 141, 550-565.

(25) Al-Dhubabian, A. A. Production of biodiesel from Soybean Oil in a Micro Scale Reactor. M.Sc. Thesis., Oregon State University, Corvallis, OR, USA. 2005. 
(26) Guan, G.; Kusakabe, K.; Moriyama, K.; Sakurai, N. Transesterification of sunflower oil with methanol in a micro-tube reactor. Ind. Eng. Chem. Res. 2009, 48, $1357-1363$.

(27) Arias, E. L. M.; Martins, P. F.; Munhoz, A. L. J.; Gutierrez-Rivera, L.; Maciel Filho, R. Continuous Synthesis and in Situ Monitoring of Biodiesel Production in Different Microfluidic Devices. Ind. Eng. Chem. Res. 2012, 51, 10755-10767.

(28) Santacesaria, E.; Di Serio, M.; Tesser, R.; Turco, R.; Tortorelli, M.; Russo, V. Biodiesel process intensification in a very simple microchannel device. Chem. Eng. Process. 2012, 52, 47-54.

(29) Chen, K.; Naveira- Cotta, C. P.; Costa Junior, J. M.; Azevedo, A. B. Microreactor fabrication by Photolithography and Analysis for Synthesis of Biodiesel. In: Proceedings of the 22st Brazilian Congress of Mechanical Engineering, Ribeirão Preto, SP, November 3-7, 2013.

(30) Naveira-Cotta, C. P.; Tostado, C. P.; Costa Jr, J. M.; Nunes, J. S.; Microreactors for Biodiesel Synthesis: Design, Fabrication, and Characterization. Heat Pipe Scie. Tech. 2015, 6 (3-4), 135-153.

(31) Santana, H. S.; Tortola. D. S.; Reis, E. M.; Silva Jr, J. L.; Taranto O. P. Transesterification reaction of sunflower oil and ethanol for biodiesel synthesis in microchannel reactor: Experimental and simulation studies. Chem. Eng. J. 2016, $302,752-762$

(32) Santana, H. S.; Tortola, D. S.; Silva Jr., J. L.; Taranto, O. P. Biodiesel synthesis in micromixer with static elements. Energy Convers. Manage. 2017, 141, 28-39. 
(33) Ma, F.; Hanna, M. A. Biodiesel production: a review. Bioresour. Technol. 1999, $70,1-15$.

(34) Schwarz, S.; Borovinskaya, E. S.; Reschetilowski, W. Base Catalyzed Ethanolysis of Soybean Oil in Microreactors: Experiments and Kinetic Modeling. Chem. Eng. Sci. 2013, 104, 610-618.

(35) Moser, B. R. Biodiesel production, properties, and feedstocks. In Vitro Cell. Dev. Biol. - Plant. 2009, 45, 229-266.

(36) Stamenković O. S.; Veličković A. V.; Veljković V. B. The production of biodiesel from vegetable oils by ethanolysis: Current state and perspectives, Fuel, 2011, 90, $3141-3155$.

(37) Boocock D. G. B.; Konar S. K.; Mao V.; Sidi H. Fast one-phase oil-rich processes for the preparation of vegetable oil methyl esters. Biomass Bioenerg. 1996, 11, 4350.

(38) Iwasaki, T.; Kawano, N.; Yoshida, J-I. Radical polymerization using microflow system: numbering-up of microreactors and continuous operation. Org. Process. Res. Dev.. 2006, 10, 1126-1131

(39) Togashi, S.; Miyamoto, T.; Asano, Y.; Endo, Y.; Yield improvement of chemical reactions by using a microreactor and development of a pilot plant using the numbering-up of microreactors. J. Chem. Eng. Jpn. 2009, 42, 512-519.

(40) Jovanovic, G.N., Paul, B.K., Parker, J., Al-Dhubabian, A., United States Patent Application, Jul. 2, 2009; US 2009/0165366 A1. 
(41) Billo, R. E.; Oliver, C. R.; Charoenwat, R.; Dennis, B. H.; Wilson, P. A.; Priest, J. W.; Beardsley, H. A cellular manufacturing process for a full scale biodiesel microreactor. J. Manuf. Syst. 2014, 37, 409-416.

(42) Su, Y.; Kuijpers, K.; Hessel, V.; Noël, T.; A convenient numbering-up strategy for the scale-up of gas-liquid photoredox catalysis in flow. React. Chem. Eng.. 2016, $1,73-81$.

(43) Yap, S. K.; Wong, W. K.; Yang Ng, N. X.; Khan, S. A.; Three-phase microfluidic reactor networks - designs, modeling and application to scale-out nanoparticlecatalyzed hydrogenations with online catalyst recovery and recycle. Chem. Eng. Sci. 2017, 169, 117-127.

(44) Han, T.; Zhang, L.; Xu, H.; Xuan, J. Factory-on-chip: Modularised microfluidic reactors for continuous mass production of functional materials. Chem. Eng. J. 2017, 326, 765-773.

(45) Mohadesi, M., Aghel, B., Maleki, M., Ansari, A., Production of biodiesel from waste cooking oil using a homogeneous catalyst: Study of semi-industrial pilot of microreactor. Renewable Energy, 2019, 136, 677-682

(46) Lopes, M. G. M.; Santana, H. S.; Andolphato, V. F.; Russo, F. N.; Silva Jr, J. L.; Taranto, O. P. 3D printed micro-chemical plant for biodiesel synthesis in milireactores. Energ Convers Manage. 2019, 184, 475-487.

(47) Costa Junior, J. M.; Naveira-Cotta, C. P.; Nunes, J. S. Fabrication and Experimental Analysis of a Micro-reactor for Biodiesel Production. In Proceedings of the 23rd International Congress of Mechanical Engineering - COBEM. Rio de Janeiro, RJ, December 6-11, 2015. 
(48) Madou, M. J. Fundamentals of Microfabrication: The Science of Miniaturization, Second Edition, 2002, CRC Press, DOI 10.1201/9781482274004

(49) Kitson, P. J.; Rosnes, M. H.; Sans, V.; Dragone, V.; Cronin, L. Configurable 3DPrintes millifluidic and microfluidic 'lab on a chip' reactionware devices. Lab. Chip. 2012, 12, 3267-3271.

(50) Shallan, A. I.; Smejkal, P.; Corban, M.; Guijt, R. M.; Breadmore, M. C. A miniaturized 3D printed polypropylene reactor for online reaction analysis by mass spectrometry. Anal. Chem. 2014, 86, 3124-3130.

(51) Bishop, G. W.; Satterwhite, J. E.; Bhakta, S.; Kadimisetty, K.; Gillette, K. M.; Chen, E., Rusling, J. F. 3D Printed Fluidic Devices for Nanoparticle Preparation and Flow-Injection Amperometry Using Integrated Prussian Blue NanoparticleModified Electrodes. Anal. Chem. 2015, 87, 5437-5443.

(52) Bineli, A. R. R.; Peres, A. P. G.; Jardini, A. L.; Maciel Filho, R. In Direct Metal Laser Sintering (DMLS): Technology for Design and Construction of Microreactors. In Proceedings of the $6^{\circ}$ Brazilian Congress of Manufacturing Engineering. Caxias do Sul, RS, BR, April 11-15, 2011.

(53) Gutmann, B.; Köckinger, M.; Glotz, G.; Ciaglia, T.; Slama, E.; Zadravec, M.; Pfanner, S.; Maier, M. C.; Gruber Wölfler, H.; Kappe, C. O. Design and 3D printing of a stainless steel reactor for continuous difluoromethylations using fluoroform. React. Chem. Eng. 2017, 2, 919-927.

(54) Scotti, G.; Nilsson, S. M. E.; Haapala, M.; Pöhö, P.; Boije af Gennãs, G.; YliKauhaluoma, J.; Kotiaho, T. A miniaturized 3D printed polypropylene reactor for online reaction analysis by mass spectrometry. React. Chem. Eng. 2017, 2, 299-303. 
(55) Costa Junior, J. M. Theoretical-experimental analysis of microreactors for waste heat recovery biodiesel synthesis. Ph.D. Thesis., Federal University of Rio de Janeiro, Rio de Janeiro, RJ, BR. 2017.

(56) Pontes, P. C.; Navaeira-Cotta, C. P.; Quaresma J. N. N. Three-dimensional reaction-convection-diffusion analysis with temperature influence for biodiesel synthesis in micro-reactors. International Journal of Thermal Sciences. 2017, 118, $1-19$.

(57) Lôbo, I. P.; Ferreira, S. L. C.; da Cruz, R. S. Biodiesel: quality parameters and analytical methods. Quím. Nova. 2009, 32, 1596-1608. 
Table Captions:

Table 1. Three Groups of all tested cases for biodiesel production considering a molar ratio of 20/1 (ethanol/oil) and catalyst concentration of $1.5 \mathrm{wt} \%$

Table 2. Water temperatures of all performed cases for biodiesel production

Table 3. Biodiesel yield at different temperatures (molar ratio of 20/1 (ethanol/oil), $1.5 \mathrm{wt} \%$ of catalyst concentration residence time: 3.88 minutes)

Table 4. Yield of ethyl esters relative to the residence time for the $\mu$ MIRHE device using an ethanol/oil molar ratio of 20/1, a catalyst concentration of $1.5 \mathrm{wt} \%$ and a fixed electric voltage of $17.5 \mathrm{~V}$ (aiming an outlet reaction temperature of $45^{\circ} \mathrm{C}$ ).

Table 5. Yield of ethyl esters for residence times of less than 1 minute in the $\mu$ MIRHE device using a 20/1 ethanol/oil molar ratio and catalyst concentration of $1.5 \mathrm{wt} \%$.

Figure Captions:

Figure 1. Schematic view of the complete $\mu$ MIRHE showing: (a) the external view of the device and (b) the internal structure of the micro reactors, the micro heat exchangers and the connections (pins and plenums).

Figure 2. Schematic views (a) of the micro reactors layer and (b) of the micro heat exchanger layer. 
Figure 3. Illustrative drawing for a possible assembly, for the scaling up production of biodiesel, comprising 100 units of $\mu$ MIRHE (1000 micro reactors and 1100 micro heat exchangers).

Figure 4. Photo of the $\mu$ MIRHE manufactured in Chromium-Cobalt utilizing the SLM additive manufacturing technique (weighs only $123 \mathrm{~g}$ )

Figure 5. Detailed geometry of the $\mu$ MIRHE in different plans. (a) CAD drawing showing the imaging planes; (b) CAD drawing showing the imaging planes in the detailed internal structure region that will be occupied by the fluids; Design CAD drawing (top) and microtomographic images (bottom) for: (c) plane 1; (d) plane 2; (e) plane 3 and (f) plane 4.

Figure 6. Optical image of the (a) cross section of the $\mu$ MIRHE; (b) dimensions of the cross sections of the channels

Figure 7. Scheme of the three consecutive steps of the transesterification reaction.

Figure 8. Schematic view of the experimental setup used in the synthesis of biodiesel

Figure 9. Profiles of the external $\mu \mathrm{MIRHE}$ temperature and outlet reaction temperature over residence time (cases 2.1 to 2.6 presented in Table 4).

Figure 10. Profile of the yield of the ethyl esters (biodiesel) over residence time for the $\mu$ MIRHE device (cases 2.1 to 2.6 presented in Table 4). 
Table of Contents

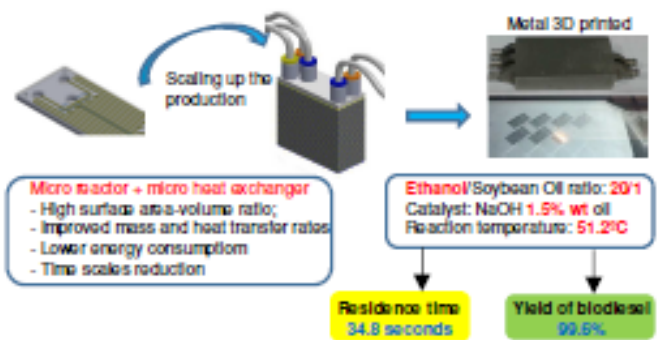

